
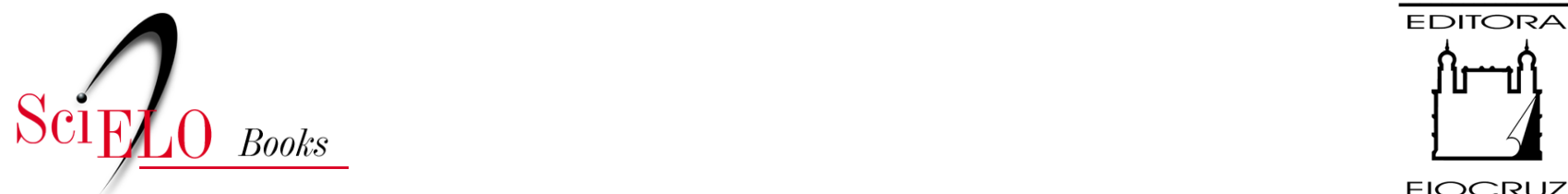

FIOCRUZ

\title{
Da Medicina Preventiva a medicina promotora
}

\author{
Roberto Passos Nogueira
}

\section{SciELO Books / SciELO Livros / SciELO Libros}

NOGUEIRA, R.P. Da Medicina Preventiva a medicina promotora. In: AROUCA, S. O dilema preventivista: contribuição para a compreensão e crítica da medicina preventiva [online]. Rio de Janeiro: Editora FIOCRUZ, 2003, pp. 175-182. ISBN: 978-85-7541-610-5. Available from: doi: 10.7476/9788575416105.0015. Also available in ePUB from: http://books.scielo.org/id/q7gtd/epub/arouca-9788575416105.epub

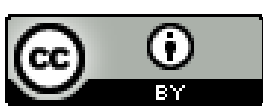

All the contents of this work, except where otherwise noted, is licensed under a Creative Commons Attribution 4.0 International license.

Todo o conteúdo deste trabalho, exceto quando houver ressalva, é publicado sob a licença $\underline{\text { Creative Commons }}$ Atribição 4.0. 


\section{Da Medicina Preventiva À medicina promotora}

\section{Roberto Passos Nogueira ${ }^{1}$}

O dilema preventivista é uma obra cuja relevância deve ser avaliada não apenas por sua contribuição à formulação de certas bases teóricas e políticas do Movimento Sanitário Brasileiro, mas também por demarcar alguns temas de uma agenda de pesquisa sobre saúde e sociedade que permaneceu muito pouco desenvolvida desde então. Quero referir-me especificamente ao processo de mudança social e das práticas de saúde pelo qual foi possível à medicina preventiva fazer prevalecer universalmente sua visão de mundo individualista e liberal ao transmutar-se em medicina promotora ("promotive medicine", em inglês), ou seja, aquela que se concentra na promoção da saúde. Proponho aqui a idéia de que, para melhor entender a medicina promotora de hoje, temos de retomar a análise feita por Arouca dos elementos ideológicos e das forças sociais que deram origem à medicina preventiva. Pretendo, assim, recuperar algumas das categorias interpretativas utilizadas por Arouca a fim de sugerir sua aplicação a uma linha de investigação acerca da medicina promotora.

A medicina preventiva filia-se à higiene na medida em que esta é entendida como a arte de conservar a vida ou, também, como uma ciência que trata da saúde com o propósito de conservá-la e aperfeiçoá-la. Sendo assim, a higiene deve acompanhar cada momento do desenvolvimento do homem, desde seu nascimento à morte, como também deve zelar para a correta realização, em termos de condições sanitárias ideais, de todas as atividades que o homem realiza: o trabalho, a alimentação, a reprodução, o lazer e assim por diante. Segundo Arouca, no século XIX, a higiene emerge

1 Pesquisador do IPEA e do Núcleo de Estudos de Saúde Coletiva da Universidade de Brasília. Todas as citações literais contidas neste texto referem-se aos capítulos III e IV do livro. 
como tal em ligação com "as ideologias liberais que afirmavam as responsabilidades individuais perante a saúde e como um conceito político nos movimentos socialistas da época". Nesse sentido, a higiene é vista como a etapa do desenvolvimento da medicina que favorece sua realização plena porque se dirige não apenas às enfermidades, mas à vida humana no seu todo: "como visão histórica, a Higiene coloca uma história teleológica da medicina, caminhando para a realização de um conceito de saúde positiva, permeando todas as condutas humanas, e que na fase moderna, ela própria, a Higiene, seria o instrumento deste 'telos' participando da formação de uma consciência sanitária". A higiene procura alargar sem limites o objeto da medicina, de modo a ir bem além do tratamento das enfermidades, e abarcar, ao fim e ao cabo, toda a vida do homem sadio; a higiene pretende controlar até mesmo o processo de produção material, em que o homem se converteu num dos fatores produtivos, como trabalhador. Assim como a dietética hipocrática, a higiene que surge no século XIX visa à mudança dos hábitos de vida dos indivíduos, conforme determinadas circunstâncias sociais e ambientais, e adapta seus preceitos e métodos ao tipo de extração social da clientela a que se dirige. Observa Arouca que "a higiene possui normas, recomendações e medidas que, se aplicadas, fariam com que este indivíduo se mantivesse em estado de saúde até a morte natural".

Esta forma de "saber aderente à vida" não é mais do que uma ilusão, denuncia Arouca, porque abstrai a causalidade estrutural das condições de existência na sociedade e, por um somatório de condutas isoladas, prescritas em nome do bem-estar, pretende afetar tudo aquilo que depende no fundo das condições históricas que criam as desigualdades sociais entre os homens. Arouca salienta, com base na leitura de Foucault e outros autores, o contraste entre a abordagem individualista da higiene e a abordagem coletivista da medicina social, tendo esta última se originado na Europa, ao final da primeira metade do século XIX, mais precisamente na Inglaterra e na França, como parte das promessas de movimentos sociais que ambicionavam a transformação revolucionária da sociedade burguesa. Representando o pensamento da então nascente medicina social brasileira, formada nos anos 70 no seio dos departamentos de medicina preventiva das faculdades de medicina, Arouca queria justamente explorar, com agudeza teóri$\mathrm{ca}$, o contraste entre essas duas correntes do pensamento social dos médicos do século XIX. 
A medicina preventiva herda da higiene a preocupação com a preservação da saúde na totalidade das dimensões ontológicas do homem e como responsabilidade social das pessoas, das famílias e da comunidade, mas introduz um viés específico que representa uma nova atitude a ser adotada por todos os médicos diante de seus pacientes. Trata-se da preocupação em evitar a ocorrência de episódios de enfermidade, a atitude preventiva, que só pode ser absorvida e implantada de forma duradoura enquanto uma proficiência profissional adquirida ao longo do período de formação acadêmica do médico. O médico preventivista não é um especialista, mas todo aquele profissional médico que aprendeu, na sua graduação, a atuar de maneira a prevenir a instalação das enfermidades, representando assim um tipo ideal de racionalidade, que torna mais eficientes os gastos realizados no sistema de saúde. Esse intento da medicina preventiva só pode se realizar a contento enquanto resultado de um convencimento educacional do médico, em que este aprende a exercer não somente suas funções curativas, mas assume por inteiro sua responsabilidade quanto a cuidar do paciente e de seus familiares segundo regras higiênicas de conservação da saúde e com a aplicação de medidas que previnam especificamente certas enfermidades físicas e psicossociais. O médico precisa, para tanto, estar apto a entender as causas das enfermidades na forma como estas aparecem em dado ambiente social e biológico, numa totalidade ecológica estruturada. O médico é quem, ao ser responsabilizado pela atitude preventiva, pode propiciar a instalação de melhores relações de vida para seu paciente nessa totalidade ecológica. A escolha do médico como ator privilegiado dessa transformação social revela, segundo sublinha Arouca, uma "posição basicamente antropológica, em que o homem, livre das determinações, instaura novas relações sociais; em que as atitudes educacionalmente formadas transformam as relações sociais, em que estas são determinadas pelos homens e por cada um em particular".

A atuação preventiva do médico deve ter em conta o modelo teórico da História Natural das Doenças elaborado por Leavell \& Clarck. Esse modelo descreve um primeiro momento do processo de adoecer, chamado pré-patológico, onde existe um equilíbrio entre três figuras destacadas, o agente, o hospedeiro e o ambiente, de acordo com as características dos fatores que estão a eles associados (por exemplo, virulência do agente, resistência do hospedeiro e condições de moradia do ambiente). O segundo momento é o da instalação da doença, com seu desenrolar fisiopatológico 
e clínico, que permite distinguir as fases pré-clínica e clínica, podendo esta última fase culminar na cura, na morte ou num estado intermediário. A atitude preventiva por parte do médico precisa ser algo presente nos dois momentos desse processo e em suas variadas etapas, porque sempre há uma possível situação piorada do estado de saúde do paciente que deve ser evitada no evoluir do processo de saúde-doença. Desse modo, a medicina preventiva atinha-se fortemente ao propósito de influenciar a conduta dos médicos, na esperança de que estes adotassem, na prestação de cuidados a seus pacientes e suas famílias, uma atitude preventivista, ou seja, de evitar metodicamente a doença.

O paradigma da história natural da doença rejeita uma causalidade simples, e assume uma visão de multicausalidade na inter-relação de fatores complexos atuantes na gênese das doenças e em todo seu processo evolutivo. Tais fatores são analisados de acordo com conceitos e dados extraídos da epidemiologia e descritos através das associações estatísticas existentes entre eles. "O mecanismo pelo qual opera a causalidade na Epidemiologia e conseqüentemente na Medicina Preventiva", observa criticamente Arouca, "é o do reducionismo, na medida em que assume as redes de causalidade em sua monótona linearidade e na homogeneidade das categorias". Com a ajuda da epidemiologia e da estatística, na medicina preventiva as relações sociais são tomadas de forma naturalizada e desprovidas de historicidade, mistificadas que são mediante sua nivelação aos demais "fatores" do ambiente, do agente e do hospedeiro: "assim, ao tornar-se natural, o paradigma deixou de ser histórico e metamorfoseou-se em mito, na medida em que uma das funções do mito é exatamente o de fazer desaparecer a história de seu objeto".

Pode-se dizer que nos anos recentes, a medicina preventiva alcançou notável popularidade e sucesso através de uma variante que é a medicina promotora. Seu ponto de atuação privilegiado não é o currículo de formação acadêmica. Ao contrário, a medicina promotora concentra esforços na utilização de uma infra-estrutura universalizada de produção e difusão de conhecimentos científicos que se estabelece como a suprema autoridade sobre o que é bom ou mal para a saúde de cada um e para a própria existência humana, fazendó da noção de risco em saúde o epicentro em torno do qual gravitam as normas de conduta que prescreve. Recolhendo e sistematizando os resultados da incessante investigação epidemiológica em escala internacional, a medicina promotora defende e difunde essas nor- 
mas que passam a influenciar decisivamente o que devem ou não fazer as pessoas, sejam estas pacientes da medicina ou simples leitores de jornais ou usuários da internet. Enfim, a medicina promotora busca promover novas atitudes perante a saúde de maneira generalizada na sociedade, e não apenas mudar o comportamento do médico. Em certo sentido, essa é uma forma de medicina que dispensa a figura do médico, porque seus objetivos dependem nada mais do que de uma adequada utilização dos canais de comunicação de massa e de alguns meios tecnológicos de educação para a saúde.

Mas, no fundo, a medicina promotora é apenas uma versão cientificamente mais desenvolvida da higiene e mantém a mesma ambição de direcionar a totalidade da existência humana em nome de um valor social único, que é a saúde. Na sua pregação dos "hábitos saudáveis", que resultam de uma responsabilização do indivíduo por cada aspecto de sua vida, a medicina promotora faz valer a mesma normalização educativa que se fazia presente na disciplina clássica da higiene do final do século XIX e começo do século XX, a que Arouca vincula o nascimento da medicina preventiva. A medicina promotora constitui um projeto similar de medicalização da totalidade da existência humana e não só da dimensão da doença; uma medicalização que pode dispensar o médico, pois tem a capacidade de moldar a seus propósitos a cultura cientificista contemporânea, afetando diretamente o modo como as pessoas cuidam de seu corpo e de sua saúde.

Quando Arouca escreveu sua tese, a noção de risco em saúde não havia ainda ganhando todo o vigor e influência que passou a exibir nas duas décadas seguintes, com o desenvolvimento ulterior tanto da medicina preventiva propriamente dita quanto da medicina promotora. As avaliações freqüentes feitas em relação a grupos de risco, a fatores de risco e a comportamentos de risco vieram a ser tornar um dos objetivos da pesquisa epidemiológica, sendo precisadas de maneira mais ou menos sofisticada com base em métodos estatísticos. Embora a caracterização do que seja um risco continue bastante ambígua, conforme notam certas abordagens sociológicas, sendo, inclusive, sujeita a polêmicas entre os especialistas, a avaliação de risco veio a dominar por completo todo o cenário técnico da elaboração de normas e medidas de prevenção de enfermidades e de promoção da saúde. Na medicina preventiva, a categoria de risco é atualmente usada para justificar a aplicação de exames em massa para detecção de câncer de mama, colo de útero e de próstata, e, crescentemente, para ava- 
liar predisposições genéticas ao desenvolvimento de certas enfermidades. Por outro lado, nas campanhas de promoção da saúde, risco é entendido de forma simplificada como probabilidade de ocorrência de um evento potencialmente danoso à saúde, aparecendo para sustentar os esforços de modificar a dieta das pessoas, parar de fumar, reduzir o consumo de álcool, eliminar o uso de drogas e incentivar a adoção do sexo seguro.

A pesquisa epidemiológica e seu uso pelos médicos e outros agentes parece criar, diante de condutas caracterizadas como de risco, uma base universal de julgamento moral sobre o comportamento humano. As condutas tidas como moralmente responsáveis são apresentadas como o oposto das condutas de risco. O caso prototípico é o do comportamento sexual correto face ao risco de transmissão de Aids, mas a intenção moralizadora se estende a muitos outros exemplos. Com isso, a noção de risco é empregada em associação constante com a noção de responsabilidade pessoal, de tal modo a gerar, quando generalizada, uma relação não apenas de causalidade, mas uma acepção moral, indicando uma falha de comportamento, que potencialmente culpabiliza ou até mesmo criminaliza as pessoas que se deixam enfermar. É tanta a ênfase dada a cada fator de risco, que a gênese das enfermidades pode perder sua conexão com uma pressuposta rede de fatores causais. De fato, as campanhas de promoção de saúde parecem ser tão mais eficazes quanto mais essa multicausalidade possa ser obscurecida para os leigos. Aqui novamente reaparece o individualismo liberal que insinua que cada indivíduo é, em última instância, responsável pelo seu estado de saúde e pelas enfermidades que lhe acometem.

Por tudo isso, na medicina promotora, a noção de risco não costuma ser analisada à luz de uma multicausalidade tal como a descrita na história natural da doença. Este paradigma tem sua utilidade pedagógica restrita ao convencimento dos médicos, que precisam de um esquema interpretativo mais complexo que os ajudem a se responsabilizar pelos aspectos preventivos da saúde de seus pacientes. A medicina promotora também tem suas justificativas teóricas sustentadas no paradigma da história natural da doença, já que surge como uma formalização autônoma da chamada prevenção primária, como maneira inespecífica de promover a saúde. Mas, na medida em que a medicina promotora se volta primariamente para o convencimento dos leigos, levando a que estes identifiquem uma atitude ideal para prevenção de riscos de saúde, a complexidade do esquema pedagógico de Leavell \& Clarck pode ser omitida; basta admitir-se implicitamente uma 
causalidade de fatores simples e até uma redução monocausal (por exemplo, "fumar causa câncer de pulmão") e, para tanto, basta que a noção de fator de risco ou de conduta de risco seja bem estabelecida e que a norma de conduta pertinente seja bem clara. É a autoridade da ciência em geral (e dos achados científicos) e não necessariamente a autoridade do médico que é invocada aquii para justificar o nexo causal.

Para concluir esses breves comentários sobre a obra de Arouca, quero sublinhar que sua crítica da medicina preventiva manteve a predileção pela alternativa configurada pela medicina social e por sua história política. Hoje já não estamos tão seguros de que, no Brasil, a saúde coletiva, como herdeira do legado da medicina social do século XIX, ainda sustenta a validade desse tipo de contraste, de tal modo a se diferenciar da medicina preventiva e de suas vertentes enquanto uma verdadeira alternativa teórica e política. O que aconteceu no pensamento sanitário, político e filosófico ao longo dos trinta anos que nos separam da produção daquela obra não mais nos permite fiar por inteiro no poder explicativo e heurístico que Arouca estabeleceu entre a abordagem individualista da medicina preventiva (e que podemos estender à medicina promotora) e a abordagem coletivista da medicina social. Os motivos são variados e deles somente posso fazer breve menção nesse reduzido espaço de discussão. Em primeiro lugar, prevalecem hoje razões de ordem prática e organizacional que fazem que os métodos da medicina preventiva e da medicina promotora sejam amplamente adotados e justificados como avanços efetivos, como acontece, por exemplo, no Programa de Saúde da Família. Mas deve-se argumentar, em contraposição, que as opções práticas seguidas pelo movimento da Reforma Sanitária, com a implantação do sus, não deveriam obstruir os caminhos de uma pertinente crítica social da saúde. Em segundo lugar, cabe ser mencionada a emergência de uma nova sensibilidade cultural, na qual as questões da subjetividade, da ética e da autonomia individual ganharam proeminência no combate às tendências mais cruéis do neocapitalismo globalizado. Essa compreensão leva-nos hoje a pôr em primeiro plano a discussão de temas tais como os originados da ética dos transplantes e da humanização do cuidado em saúde. Quanto a esses aspectos, a emergência de uma compreensão que abraça noções denotativas de individualidade e subjetividade não deveria obscurecer a dimensão social da saúde. Por tudo isso, não nos parece adequado e contemporâneo colocar agora o debate acerca da medicina promotora em termos da oposição entre uma 
visão individualista do processo de saúde-doença e uma visão coletivista. No entanto, a releitura da obra de Arouca concita-nos a refletir acerca da possibilidade de reabrir espaços de crítica social, provida de suficiente radicalidade filosófica, para continuar a realizar o estudo da problemática da saúde em sua totalidade. Entendo que desconstruir as bases cientificistas da medicina promotora pode ser uma das iniciativas dessa vertente de pensamento social em saúde, podendo ser inspirada, como busquei indicar aqui, pela notável criatividade da obra de Arouca. 